\title{
NKCC1 Upregulation Disrupts Chloride Homeostasis in the Hypothalamus and Increases Neuronal Activity-Sympathetic Drive in Hypertension
}

\author{
Zeng-You Ye (叶增友), ${ }^{1,2}$ De-Pei Li (李德培), ${ }^{1,3}$ Hee Sun Byun (변희(선), ${ }^{1,2}$ Li Li (李莉), ${ }^{1,2}$ and Hui-Lin Pan (潘惠麟) ${ }^{1,2,4}$ \\ ${ }^{1}$ Center for Neuroscience and Pain Research, ${ }^{2}$ Department of Anesthesiology and Perioperative Medicine, and ${ }^{3}$ Department of Critical Care, The University \\ of Texas MD Anderson Cancer Center, Houston, Texas 77030, and ${ }^{4}$ Graduate Programs in Neuroscience and Experimental Therapeutics, The University of \\ Texas Graduate School of Biomedical Sciences, Houston, Texas 77225
}

Hypertension is a major risk factor for coronary artery disease, stroke, and kidney failure. However, the etiology of hypertension in most patients is poorly understood. Increased sympathetic drive emanating from the hypothalamic paraventricular nucleus (PVN) plays a major role in the development of hypertension. $\mathrm{Na}^{+}-\mathrm{K}^{+}-2 \mathrm{Cl}^{-}$cotransporter-1 (NKCC1) in the brain is critically involved in maintaining chloride homeostasis and in neuronal responses mediated by $\mathrm{GABA}_{\mathrm{A}}$ receptors. Here we present novel evidence that the $\mathrm{GABA}$ reversal potential $\left(E_{\mathrm{GABA}}\right)$ of PVN presympathetic neurons undergoes a depolarizing shift that diminishes GABA inhibition in spontaneously hypertensive rats (SHRs). Inhibition of NKCC1, but not KCC2, normalizes $E_{\mathrm{GABA}}$ and restores GABA inhibition of PVN neurons in SHRs. The mRNA and protein levels of NKCC1, but not KCC2, in the PVN are significantly increased in SHRs, and the NKCC1 proteins on the plasma membrane are highly glycosylated. Inhibiting NKCC1 $N$-glycosylation restores $E_{\mathrm{GABA}}$ and GABAergic inhibition of PVN presympathetic neurons in SHRs. Furthermore, NKCC1 inhibition significantly reduces the sympathetic vasomotor tone and augments the sympathoinhibitory responses to $\mathrm{GABA}_{\mathrm{A}}$ receptor activation in the PVN in SHRs. These findings suggest that increased NKCC1 activity and glycosylation disrupt chloride homeostasis and impair synaptic inhibition in the PVN to augment the sympathetic drive in hypertension. This information greatly improves our understanding of the pathogenesis of hypertension and helps to design better treatment strategies for neurogenic hypertension.

\section{Introduction}

Hypertension is a well known "silent killer" and a major risk factor for coronary artery disease, stroke, and kidney failure. The etiology of essential (primary) hypertension, which accounts for $90-95 \%$ of hypertensive cases, remains largely unknown. Considerable evidence indicates that essential hypertension is initiated primarily from the CNS and is later reinforced by nonneural factors (Mancia et al., 1999; Schlaich et al., 2004). It is well recognized that sympathetic nerve activity is augmented in patients with essential hypertension (Anderson et al., 1989; Greenwood et al., 1999; Mancia et al., 1999) and in animal models of essential hypertension such as spontaneously hypertensive rats (SHRs) (Judy et al., 1976; Allen, 2002; Li and Pan, 2007a). Neurons in the hypothalamic paraventricular nucleus (PVN) play an important role in controlling sympathetic drive through their

Received March 19, 2012; revised April 26, 2012; accepted May 5, 2012.

Author contributions: H.-L.P. designed research; Z.-Y.Y., D.-P.L., H.S.B., and L.L. performed research; Z.-Y.Y., D.-P.L., H.S.B., and L.L. analyzed data; Z.-Y.Y. and H.-L.P. wrote the paper.

This study was supported by the National Institutes of Health (Grant HL077400), a postdoctoral fellowship from the American Heart Association-South (entral Affiliate (to Z.-Y.Y.), and the N.G. and Helen T. Hawkins Endowment (to H.-L.P.).

Correspondence should be addressed to Dr. Hui-Lin Pan, Department of Anesthesiology and Perioperative Medicine, Unit 110, The University of Texas MD Anderson Cancer Center, 1515 Holcombe Boulevard, Houston, TX 770304009. E-mail: huilinpan@mdanderson.org.

DOI:10.1523/JNEUROSCI.1346-12.2012

Copyright $\odot 2012$ the authors $\quad 0270-6474 / 12 / 328560-09 \$ 15.00 / 0$ projections to sympathetic-related neurons in the spinal cord and the brainstem (Swanson and Sawchenko, 1983; Kannan et al., 1989; Martin and Haywood, 1993; Pyner and Coote, 2000). The hypothalamus, especially the PVN, is critically involved in the development of hypertension (Ciriello et al., 1984; Eilam et al., 1991), and the hyperactivity of PVN presympathetic neurons contributes to elevated sympathetic outflow in hypertension (Allen, 2002; Li and Pan, 2007a,b). The excitability of PVN presympathetic neurons is tonically regulated by excitatory glutamatergic and inhibitory GABAergic inputs, and removal of GABAergic inhibition in the PVN profoundly increases sympathetic outflow and blood pressure (Martin and Haywood, 1993; Li and Pan, 2007a). In SHRs, tonic GABAergic inhibition in the PVN is impaired (Li and Pan, 2006, 2007a). Although the diminished GABAergic inhibition in the PVN may result from reduced presynaptic $\mathrm{GABA}$ release, decreased $\mathrm{GABA}_{\mathrm{A}}$ receptor number, or the loss of GABAergic neurons in hypertension, none of these proposed mechanisms has been substantiated.

$\mathrm{GABA}_{\mathrm{A}}$ receptors are ligand-gated ion channels with a predominant permeability to $\mathrm{Cl}^{-}$and a slight permeability to $\mathrm{HCO}_{3}^{-}$(Bormann et al., 1987; Kaila and Voipio, 1987; Kaila et al., 1993). The strength and polarity of GABA actions in the brain are largely determined by the intracellular $\mathrm{Cl}^{-}$concentration $\left(\left[\mathrm{Cl}^{-}\right]_{\mathrm{i}}\right)$, which is primarily maintained by cation-chloride cotransporters. The $\mathrm{Na}^{+}-\mathrm{K}^{+}-2 \mathrm{Cl}^{-}$cotransporter-1 (NKCC1) and $\mathrm{K}^{+}-\mathrm{Cl}^{-}$cotransporter-2 (KCC2) maintain a fine balance 
between chloride influx (NKCC1) and efflux (KCC2) and determine the neuronal responses mediated by ionotropic GABA receptors in the brain (Rivera et al., 1999; Payne et al., 2003). Disruption of chloride homeostasis in certain brain regions causes neurological disorders such as epilepsy (Dzhala et al., 2005; Pathak et al., 2007). Here we present evidence for a previously unrecognized mechanism underlying diminished GABAergic synaptic inhibition in the PVN and increased sympathetic vasomotor tone in hypertension. This mechanism involves disrupted chloride homeostasis of PVN presympathetic neurons, which is caused by upregulation of NKCC1 in hypertension. Interestingly, our study also reveals that increased $\mathrm{N}$-glycosylation of NKCC1 on the plasma membrane augments NKCC1 activity and decreases GABA synaptic inhibition in the PVN in SHRs. These findings provide new mechanistic understanding of the neurobiological basis of hypertension and help the design of new strategies for treatment of neurogenic hypertension.

\section{Materials and Methods}

Animals and retrograde labeling of PVN presympathetic neurons. Male Wistar-Kyoto (WKY) rats and SHRs (13 weeks old, Harlan) were used in this study. The surgical procedures and experimental protocols were approved by the Institutional Animal Care and Use Committee of The University of Texas MD Anderson Cancer Center and conformed to the National Institutes of Health guidelines on the ethical use of animals. Arterial blood pressure (ABP) was measured daily in each rat for at least 1 week before performing experiments by using a noninvasive tail-cuff system (IITC Life Science, Inc.). The systolic ABP was significantly higher in SHRs (213.00 $\pm 4.77 \mathrm{mmHg}, n=28)$ than in age-matched WKY rats $(133.73 \pm 2.12 \mathrm{mmHg}, n=19)$.

PVN presympathetic neurons were retrogradely labeled by using fluorescent microspheres (FluoSpheres) injected into the intermediolateral cell column in the spinal cord or the rostral ventrolateral medulla (RVLM) as described previously (Li et al., 2003; Li and Pan, 2005). After injection, the rats were returned to their cages for $3-5 \mathrm{~d}$ to allow for the FluoSpheres to be transported to the PVN.

Celiac ganglionectomy and blood pressure measurements with telemetry. Celiac ganglionectomy (CGx) or sham surgery was performed aseptically in SHRs anesthetized with 2\% isoflurane as described previously (Ye et al., 2011; Li et al., 2012). The celiac plexus and all visible nerves were dissected and stripped as completely as possible. In sham control rats, the celiac ganglion plexus was exposed without being disturbed. The blood pressure was measured in freely moving SHRs with the telemetry system (Telemetry Research Ltd.) as described previously (Ye et al., 2011). Briefly, the Millar catheter was inserted into the abdominal aorta and the transmitter body was implanted in the abdominal cavity. The rats were housed individually, and the blood pressure signal in freely moving rats was monitored through the receiver. The blood pressure data were collected every $2 \mathrm{~d}$ starting at day 5 after surgery and analyzed with a data acquisition system (LabChart; AD Instruments) $5 \mathrm{~d}$ after surgery. The rats were used for brain slice recordings $15 \mathrm{~d}$ after CGx or sham surgery.

Brain slice preparation and electrophysiological recordings. The rat was rapidly decapitated under isoflurane anesthesia. The brain was quickly removed and sectioned (300 $\mu \mathrm{m}$ thick) using a vibrating microtome in ice-cold artificial CSF solution containing (in mM) $126 \mathrm{NaCl}, 3 \mathrm{KCl}, 1.5$ $\mathrm{MgCl}_{2}, 2.4 \mathrm{CaCl}_{2}, 1.2 \mathrm{NaH}_{2} \mathrm{PO}_{4}, 10$ glucose, and $26 \mathrm{NaHCO}_{3}$ saturated with $95 \% \mathrm{O}_{2}$ and $5 \% \mathrm{CO}_{2}$. The slices were preincubated in the artificial $\mathrm{CSF}$ at $34^{\circ} \mathrm{C}$ for at least $1 \mathrm{~h}$ before recording. To verify the injection and diffusion sites of FluoSpheres, the spinal cord was removed and sectioned at the injection level and viewed under a microscope immediately after the rat was killed (Ye et al., 2011). Rats in which the injection site was not located within the intermediolateral cell column of the spinal cord and the RVLM were excluded from the analysis.

The labeled PVN neurons were visualized under an upright microscope (BX51WI, Olympus) equipped with epifluorescence and infrared differential interference contrast optics. All recordings were obtained at $34^{\circ} \mathrm{C}$ using borosilicate glass microelectrodes (resistance, 4-6 M $\Omega$ ).
$\mathrm{Cl}^{-}$-impermeable gramicidin-perforated recordings were performed (Ebihara et al., 1995; Kyrozis and Reichling, 1995) using a pipette solution containing (in mM) $140 \mathrm{CsCl}, 5$ EGTA, and 10 HEPES, pH 7.4 (Sung et al., 2000). Gramicidin was freshly dissolved in DMSO and then diluted into the pipette solution to obtain a final concentration of $50 \mu \mathrm{g} / \mathrm{ml}$. The fluorescent dye Lucifer yellow $(0.5 \mathrm{mg} / \mathrm{ml})$ was added to the pipette solution to provide a way of determining whether the cell membrane was ruptured during recording.

To determine the $E_{\mathrm{GABA}}$, the GABA currents were evoked by puff application of GABA and recorded at a series of holding potentials ranging from -100 to $-40 \mathrm{mV}$ at $10 \mathrm{mV}$ increments under voltage-clamp conditions. The duration of GABA puff application was kept $<15 \mathrm{~ms}$ to prevent the induction of $\mathrm{HCO}_{3}^{-}$currents by GABA (Grover et al., 1993; Kaila et al., 1997). CGP55845 (2 $\mu \mathrm{M})$ and tetrodotoxin (TTX, $1 \mu \mathrm{M})$ were added to the bath solution to block $\mathrm{GABA}_{\mathrm{B}}$ receptors and action potential-dependent synaptic activity, respectively. To record spontaneous firing activity, cell-attached recording was performed without the use of TTX. Signals were processed using Axopatch 700B amplifier (Molecular Devices), filtered at $1-2 \mathrm{kHz}$, and digitized at $20 \mathrm{kHz}$.

Bumetanide, furosemide, gabazine (SR95531), GABA, and tunicamycin were purchased from Sigma-Aldrich. Bicuculline and TTX were obtained from Ascent Scientific, and CGP55845 was obtained from Tocris Bioscience.

Western blots and deglycosylation of NKCC1 proteins. The hypothalamic slices were sectioned $1.08-2.12 \mathrm{~mm}$ caudal to the bregma, and the PVN tissues were micro-punched bilaterally with a slice punch $(0.5 \mathrm{~mm}$ diameter) following stereotactic coordinates: $0.5 \mathrm{~mm}$ lateral to the midline and $1.7-2.5 \mathrm{~mm}$ ventral to the surface of the cortex (Paxinos and Watson, 1998). Total and membrane protein were extracted using a ProteoExtract Subcellular Proteome Extraction Kit (Calbiochem) according to the manufacturer's instructions (Ye et al., 2011). The samples were subjected to $12 \%$ SDS-PAGE and transferred to polyvinylidene difluoride membrane (Immobilon $\mathrm{P}$, Millipore). The immunoblots were probed with a rabbit anti-KCC2 antibody (1:3000, Millipore) (Payne et al., 1996), T4 monoclonal anti-NKCC1 antibody (1:1000, Developmental Studies Hybridoma Bank, University of Iowa, Iowa City, IA) (Lytle et al., 1995), anti- $\beta$ actin antibody (A5441, 1:2000, Sigma-Aldrich), and GAPDH (MAB374, Millipore). ECL kit (GE Healthcare Life Sciences) was used to detect the protein bands, which were quantified by the ImageJ software (NIH). The amounts of NKCC1 and KCC2 proteins were quantified by normalizing the optical density of their protein band to that of $\beta$-actin or GAPDH in the same samples. The mean values of NKCC1 and KCC2 proteins in control rats were considered to be 1 .

Aliquots of the PVN membrane fraction from SHRs were treated with the peptide $N$-glycosidase F (PNGase F; New England Biolabs) according to the manufacturer's instructions. Briefly, a $20 \mu \mathrm{g}$ aliquot of the membrane fraction was diluted in $20 \mu \mathrm{l}$ of glycoprotein denaturing buffer $(0.5 \%$ SDS and $0.04 \mathrm{~m} \mathrm{DTT})$, and denatured by heating at $100^{\circ} \mathrm{C}$ for 10 min (Gerelsaikhan et al., 2006). Then, a total reaction volume of $40 \mu \mathrm{l}$ in G7 reaction buffer (50 mu sodium phosphate, $\mathrm{pH} 7.5$ ) with $1 \% \mathrm{NP}-40$ and $4 \mu \mathrm{l}$ of PNGase $\mathrm{F}$ was incubated at $37^{\circ} \mathrm{C}$ for $1 \mathrm{~h}$. In vehicle-treated samples, PNGase F's storage buffer ( $50 \mathrm{~mm} \mathrm{NaCl}, 20 \mathrm{~mm}$ Tris- $\mathrm{HCl}$ at $\mathrm{pH}$ 7.5, $5 \mathrm{mM} \mathrm{Na}_{2}$ EDTA and 50\% glycerol) was substituted for PNGase F.

Quantification of NKCC1 mRNA levels. PVN tissues were obtained using the micro-punch method as described above. Total RNA was extracted using a Purelink total RNA purification system (Invitrogen) with on-column DNase I digestion. For each sample, $2 \mu \mathrm{g}$ of total RNA was reverse-transcribed for $60 \mathrm{~min}$ at $37^{\circ} \mathrm{C}$ with random primers and M-MLV reverse transcriptase. The cDNA was prepared using a Superscript III first-stand synthesis kit (Invitrogen). Quantitative PCR was performed using the iQ5 real-time PCR detection system with SYBR Green PCR kit (Bio-Rad). All samples were run in duplicate using an annealing temperature of $60^{\circ} \mathrm{C}$, and the experiments were repeated at least once. The sequences of the primer pairs were as follows: NKCC1 (NM_031798), 5' -TCAGCCACACTCTCATCAGC-3' (forward) and 5' AACCTTTCGCAAACATCTGG-3' (reverse); KCC2 (NM_134363), 5' TCTCCATCCTGGCCATCTAC-3' (forward) and 5' -TCACCGTCTCAT TTCCTTCC-3' (reverse); GAPDH (NM_001001303), 5' -TGTGTCCG TCGTGGATCTGA-3' (forward) and 3'-TTGCTGTTGAAGTCGCAG 
GAG-5' (reverse). The housekeeping gene GAPDH was used to normalize the differences in cDNA aliquots. The mean values of the mRNA levels of NKCC1 and KCC2 in control rats were considered to be 1 .

Recordings of lumbar sympathetic nerve activity and hemodynamics. Rats were anesthetized by $2 \%$ isoflurane in $\mathrm{O}_{2}$ followed by intraperitoneal injection of a mixture of $\alpha$-chloralose $(60-75 \mathrm{mg} / \mathrm{kg})$ and urethane $(800 \mathrm{mg} / \mathrm{kg})$. The adequate depth of anesthesia was confirmed before surgery by the absence of both corneal reflexes and paw withdrawal responses to a noxious pinch. The trachea was cannulated for mechanical ventilation using a rodent ventilator with $100 \% \mathrm{O}_{2}$. $\mathrm{ABP}$ was monitored by a pressure transducer through a catheter placed into the left femoral artery. Heart rate (HR) was measured by triggering from the pulsatile blood pressure. A small branch of the left lumbar postganglionic sympathetic nerve was isolated under an operating microscope through a retroperitoneal incision ( $\mathrm{Li}$ and Pan, 2007a; Li et al., 2012). The nerve signal was amplified and bandpass filtered using an alternating current amplifier (model P511; Grass Instruments). The lumbar sympathetic nerve activity (LSNA) and ABP were recorded using a 1401-PLUS analog-todigital converter and Spike2 system (Cambridge Electronic Design). Background electrical noise, determined by a complete suppression of LSNA with administration of phenylephrine $(20 \mu \mathrm{g} / \mathrm{kg}$, i.v. $)$ before euthanasia, was subtracted from the integrated values of LSNA.

Intracerebroventricular injection and PVN microinjection. A guide cannula was placed through a $2 \mathrm{~mm}$ burr hole drilled in the skull over the lateral ventricle $1.5 \mathrm{~mm}$ lateral to the midline, $1.0 \mathrm{~mm}$ caudal to the bregma, and $3.0 \mathrm{~mm}$ ventral to the dura. Intracerebroventricular injections were performed using a Hamilton syringe connected with an injection cannula (Ye et al., 2011), which was advanced $3.5 \mathrm{~mm}$ ventrally from the surface of the dura. The tip of the injection cannula protruded 0.5 $\mathrm{mm}$ beyond the tip of the guide cannula. Each injection consisted of $10 \mu \mathrm{l}$ of a solution delivered over a period of a minute. Bumetanide was initially dissolved in DMSO and then diluted with artificial CSF $(0.5 \%$ DMSO) in a concentration of $200 \mu \mathrm{M}$. To ensure that the entire injection had been delivered, the injection cannula was left in place for another minute before it was removed.

For PVN microinjections, rats were placed in a stereotactic frame and their brains were exposed at the level of the hypothalamus. A glass microinjection pipette (tip diameter $20-30 \mu \mathrm{m}$ ) was advanced into the PVN following the stereotactic coordinates (Li and Pan, 2007a; Li et al., 2012): $1.6-2.0 \mathrm{~mm}$ caudal to the bregma, $0.5 \mathrm{~mm}$ lateral to the midline, and $7.0-7.5 \mathrm{~mm}$ ventral to the dura. The injection sites of the PVN were verified by the depressor responses to microinjection of $5.0 \mathrm{nmol}$ GABA $(20 \mathrm{nl}, 250 \mathrm{~mm})$. The microinjection was done using a calibrated microinjection system (Nanoject II; Drummond Scientific). The PVN vasomotor site was considered to have been located when GABA injection decreased the mean ABP by at least $10 \mathrm{mmHg}$ ( $\mathrm{Li}$ and Pan, 2007a). The stereotactic coordinates at which the prior GABA microinjection elicited the greatest depressor responses were used in the same rat for the subsequent microinjection of muscimol $(1.0 \mathrm{nmol}, 50 \mathrm{nl})$. The location of the pipette tip and diffusion of the drugs in the PVN were determined by including 5\% FluoSpheres $(0.04 \mu \mathrm{m}$; Invitrogen $)$ in the injection solution. The brain was removed rapidly at the end of the experiment, and fixed in $10 \%$ buffered formalin solution overnight. Frozen coronal sections ( $40 \mu \mathrm{m}$ thick) were cut using a freezing microtome and mounted on slides. Rhodamine-labeled fluorescent regions were identified using an epifluorescence microscope and plotted on standardized sections from the Paxinos and Watson (1998) atlas. Rats in which the microinjection occurred outside the PVN were excluded from the analysis.

Data analysis. Data are presented as means \pm SEM. The junction potential was corrected off-line on the basis of the composition of the internal and external solutions used for recordings. The $E_{\mathrm{GABA}}$ was determined by using linear regression to calculate a best-fit line for the voltage dependence of GABA-induced currents. The intercept of the current-voltage line with the abscissa was taken as the $E_{\mathrm{GABA}}$, and then $\left[\mathrm{Cl}^{-}\right]_{\mathrm{i}}$ was calculated using the Nernst equation (Kakazu et al., 2000). For electrophysiological experiments, only one neuron was recorded from one brain slice and at least 3 rats were used in each group. Student's $t$ test was used to compare two datasets. For comparisons of more than a

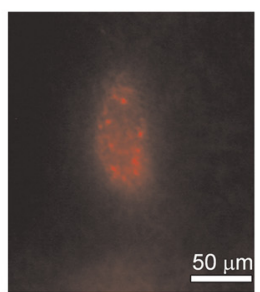

b
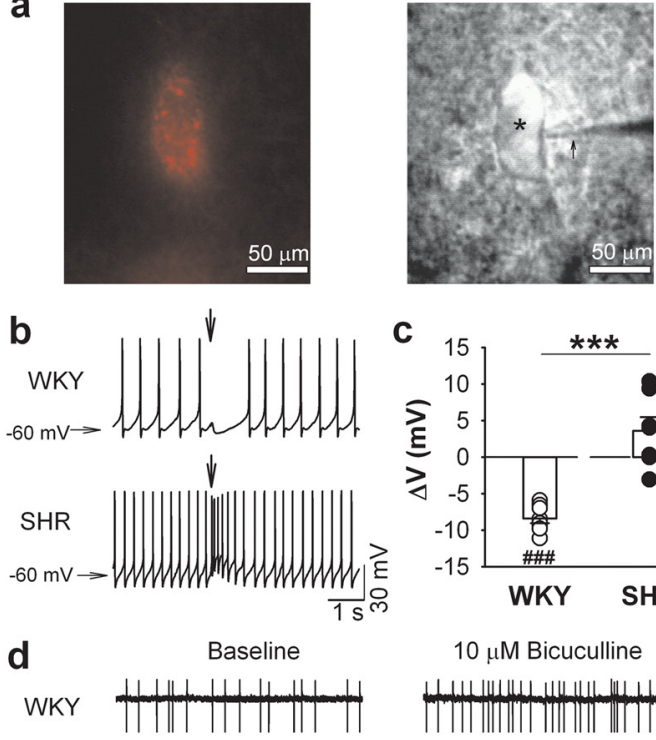

C

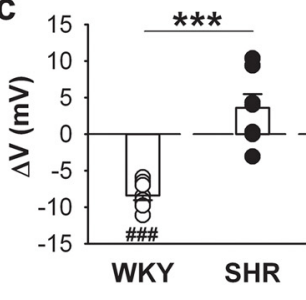

$10 \mu \mathrm{M}$ Bicuculline
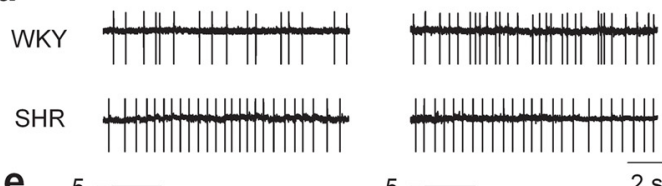

e
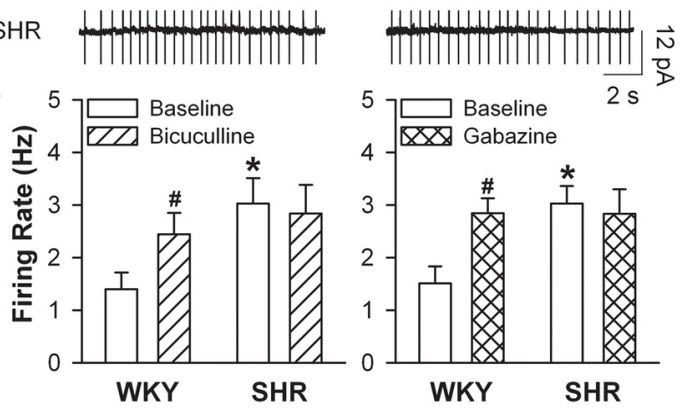

Figure 1. GABA inhibition of PVN presympathetic neurons is diminished in hypertension. $\boldsymbol{a}$, A FluoSphere-labeled PVN neuron (*) viewed with fluorescence illumination (left) and infrared differential interference contrast optics (right) in the live brain slice of an SHR. The recording electrode was marked with an arrow. $\boldsymbol{b}$, Original recordings show changes of membrane potentials $(\Delta V)$ induced by GABA puff application to labeled PVN neurons from 1 WKY rat and 1 SHR. The arrows show the time of GABA (300 $\mu \mathrm{m}$ ) puff application. c, Mean changes of $\Delta V$ induced by GABA application to labeled PVN neurons from WKY rats ( $n=8$ neurons) and SHRs ( $n=9$ neurons). $\boldsymbol{d}$, The firing activity of labeled PVN neurons before and during bath application of bicuculline in 1 WKY rat and 1 SHR. e, Mean firing activity of PVN neurons before and during application of bicuculline (WKY, $n=6$ neurons; SHR, $n=9$ neurons) or gabazine (WKY, $n=6$ neurons; SHR, $n=9$ neurons). ${ }^{*} p<0.05,{ }^{* * *} p<0.001$, compared with the value in WKY group. ${ }^{*} p<0.05, \# \#<0.001$, compared with the respective baseline value.

two datasets, the repeated-measures ANOVA with Dunnett's post hoc test and two-way ANOVA with Bonferroni's post hoc test were performed to compare differences within and between groups, respectively. $p<0.05$ was considered statistically significant.

\section{Results}

Diminished GABA inhibition and depolarizing shift of the $E_{\mathrm{GABA}}$ in the $\mathrm{PVN}$ in hypertension

We performed $\mathrm{Cl}^{-}$-impermeable gramicidin-perforated recordings (Ebihara et al., 1995; Kyrozis and Reichling, 1995) in 13week-old SHRs to determine changes in the GABAergic control of the excitability of PVN presympathetic neurons without altering the neurons' intracellular $\mathrm{Cl}^{-}$concentration $\left(\left[\mathrm{Cl}^{-}\right]_{\mathrm{i}}\right)$. Puff applied GABA $(300 \mu \mathrm{M})$ directly to the retrogradely labeled spinally projecting neurons in the PVN consistently hyperpolarized the membrane potential and inhibited the firing activity of all neurons in normotensive WKY rats $(n=8$ neurons; $p<0.001$, $t=13.39, \mathrm{df}=7$; Fig. $1 a-c)$. In contrast, GABA either had a small hyperpolarizing effect or caused a paradoxical depolarization of 
a
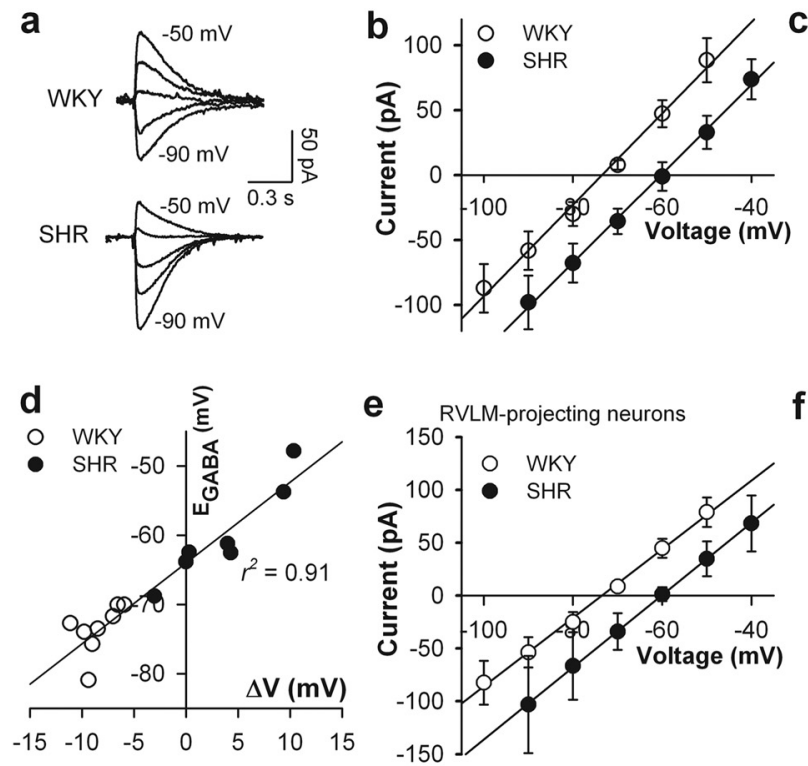

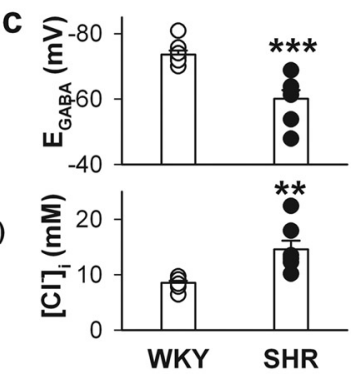

f RVLM-projecting neurons

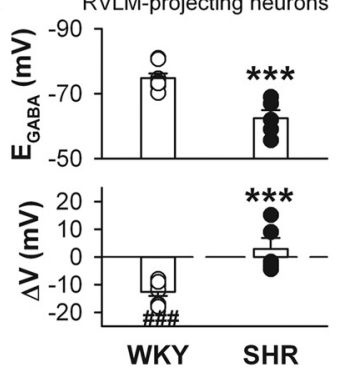

Figure 2. Depolarizing shift of the $E_{G A B A}$ and diminished GABA inhibition of PVN presympathetic neurons in hypertension. $\boldsymbol{a}, \boldsymbol{b}$, Original perforated recordings $(\boldsymbol{a})$ and $I-V$ plots $(\boldsymbol{b})$ show the $E_{\mathrm{GABA}}$ of GABA currents of spinally projecting PVN neurons from 1 WKY rat and 1 SHR. c, Mean changes in the $E_{\mathrm{GABA}}$ and derived $\left[\mathrm{Cl}^{-}\right]_{\mathrm{i}}$ of spinally projecting PVN neurons in WKY rats ( $n=8$ neurons) and SHRs ( $n=7$ neurons). $\boldsymbol{d}$, Linear relationship between changes in the $E_{\mathrm{GABA}}$ and GABA-induced membrane potentials $(\Delta V)$ of spinally projecting PVN neurons in WKY rats and SHRs. e, I-V plots show GABA currents recorded at different holding potentials of RVLM-projecting PVN neurons from WKY rats and SHRs ( $n=7$ neurons in each group). $f$, Mean changes in $E_{\mathrm{GABA}}$ and $\Delta V$ induced by puff GABA application to RVLM-projecting PVN neurons from WKY rats and SHRs ( $n=7$ neurons in each group). ${ }^{* *} p<0.05$, ${ }^{* * *} p<0.001$, compared with the WKY group.
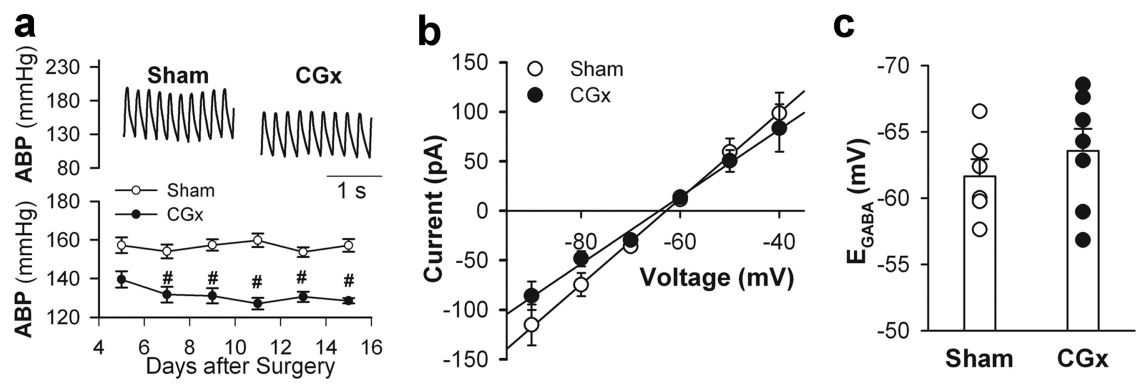

Figure 3. Lowering blood pressure with celiac ganglionectomy does not affect the $E_{G A B A}$ of PVN presympathetic neurons in hypertension. $\boldsymbol{a}$, Original blood pressure recordings and mean ABP in SHRs that underwent $C \mathrm{Gx}$ or sham surgery $(n=6$ rats in each group). $\boldsymbol{b}, \boldsymbol{c}, I-V$ plots $(\boldsymbol{b})$ and bar graph (c) show the $E_{\mathrm{GABA}}$ of spinally projecting PVN neurons from SHRs that underwent $C \mathrm{Gx}$ or sham surgery ( $n=7$ neurons in each group). ${ }^{\#} p<0.05$, compared with the corresponding value in sham-operated SHRs.

rons) displayed a significant depolarizing shift $(\sim 13 \mathrm{mV})$ compared with that from WKY rats $(n=8$ neurons; $p<0.001, t=$ $4.82, \mathrm{df}=13$; Fig. $2 a-c)$. The $\left[\mathrm{Cl}^{-}\right]_{\mathrm{i}}$ of the PVN neurons, calculated from the $E_{\mathrm{GABA}}$ with the Nernst equation, was significantly higher in SHRs than in WKY rats $(14.59 \pm 1.58$ versus $8.55 \pm 0.38 \mathrm{~mm} ; p<$ $0.01, t=3.72, \mathrm{df}=6$; Fig. $2 c)$. The change in the GABA-induced membrane potential was closely correlated with the $E_{\mathrm{GABA}}$ in PVN neurons recorded from WKY rats and SHRs $\left(r^{2}=0.91 ; p<\right.$ 0.001, $F=128.17$, df = 14; Fig. $2 d$ ).

PVN neurons projecting to the intermediolateral cell column of the spinal cord and the RVLM are largely nonoverlapping (Pyner and Coote, 2000). The diminished GABA inhibition and the depolarizing shift in $E_{\mathrm{GABA}}$ also occurred in RVLM-projecting PVN neurons in SHRs (Fig. 2e,f). These data indicate that the chloride homeostasis is altered in PVN presympathetic neurons, which could account for the loss of GABAergic synaptic inhibition in hypertension.

To determine whether the depolarizing shift in the $E_{\mathrm{GABA}}$ of PVN neurons is the cause of or an adaptive response to high blood pressure in SHRs, we determined the $E_{\mathrm{GABA}}$ of spinally projecting PVN neurons in SHRs after lowering the ABP by performing CGx (Ye et al., 2011; Li et al., 2012). CGx, but not sham surgery, significantly decreased the mean ABP in SHRs for at least 2 weeks $(n=6$ rats in each group; $p<0.01, F=186.20$, $\mathrm{df}=71$, two-way ANOVA test; Fig. $3 a$ ). However, the $E_{\mathrm{GABA}}$ of spinally projecting PVN neurons did not differ significantly between CGx and sham groups $(n=7$ rats; $p>0.05, t=0.90, \mathrm{df}=11$; Fig. $3 b, c)$, suggesting that altered GABA signaling appears not to be an adaptive response to high blood pressure. the membrane potential of PVN neurons in SHRs $(n=9$ neurons; $p>0.05, t=1.93$, df $=8$; Fig. $1 b, c)$.

We used cell-attached recordings to determine changes in tonic GABAergic inhibition of the firing activity of spinally projecting PVN neurons in WKY rats and SHRs. The basal firing rate of the PVN neurons was significantly higher in SHRs $(n=9$ neurons) than in WKY rats $(n=6$ neurons; $p<0.05, t=2.46$, $\mathrm{df}=13$; Fig. $1 d, e$ ). Bath application of the $\mathrm{GABA}_{\mathrm{A}}$ receptor antagonists bicuculline $(10 \mu \mathrm{M})$ or gabazine $(20 \mu \mathrm{M})$ significantly increased the firing rate of PVN neurons in WKY rats $(n=6$ neurons; $p<0.05, t=3.55, \mathrm{df}=5$ ). However, bicuculline or gabazine did not significantly affect the firing rate of PVN neurons in SHRs ( $n=9$ neurons; $p>0.05, t=1.35$, df = 8; Fig. $1 d, e)$.

We then used gramicidin-perforated patch-clamp recordings to determine the GABA reversal potential $\left(E_{\mathrm{GABA}}\right)$ as a readout of GABA-mediated $\left[\mathrm{Cl}^{-}\right]_{\mathrm{i}}$ activity (Ebihara et al., 1995) in spinally projecting PVN neurons. PVN neurons from SHRs ( $n=7$ neu-

\section{Increased NKCC1 activity in the PVN contributes to} disrupted $\mathrm{Cl}^{-}$homeostasis in hypertension

The $\left[\mathrm{Cl}^{-}\right]_{\mathrm{i}}$ of neurons in the CNS is mainly maintained by NKCC1 and KCC2 (Williams et al., 1999; Mercado et al., 2004; Kahle et al., 2008). To determine whether NKCC1 or KCC2 is involved in the disruption of chloride homeostasis in SHRs, we assessed the $E_{\mathrm{GABA}}$ of spinally projecting PVN neurons in brain slices treated with NKCC1- or KCC2-selective inhibitors. Incubating the brain slices with bumetanide ( $n=7$ neurons; $20 \mu \mathrm{M}$ for $2-4 \mathrm{~h}$ ) at a concentration that selectively inhibits NKCC1 (Delpy et al., 2008) completely normalized the depolarizing shift in the $E_{\mathrm{GABA}}$ of PVN neurons in SHRs $(p<0.001, F=23.153$, $\mathrm{df}=21$; Fig. $4 a, b)$, whereas incubating the brain slices with the KCC2 inhibitor furosemide ( $n=8$ neurons; $200 \mu \mathrm{M}$ for $2-4 \mathrm{~h}$ ) (Hewitt et al., 2009) did not.

In bumetanide-treated brain slices from SHRs, puff application of GABA consistently hyperpolarized the membrane poten- 
a
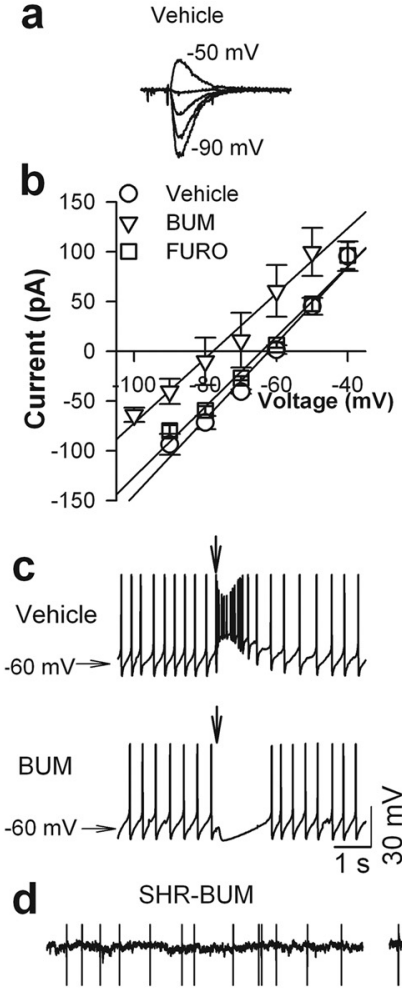

SHR-Vehicle
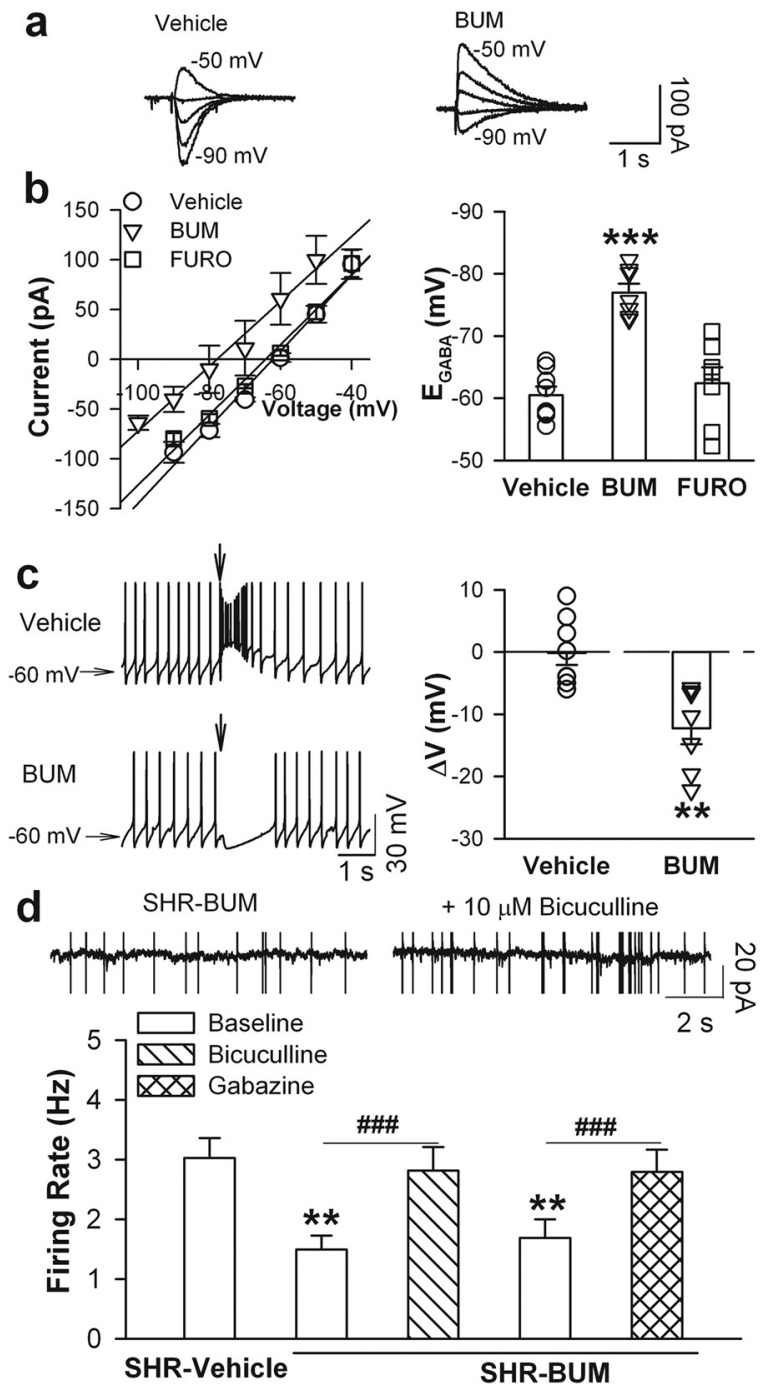

$+10 \mu \mathrm{M}$ Bicuculline

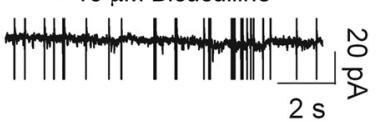

Figure 4. Increased NKCC1 activity contributes to the depolarizing shift in the $E_{\mathrm{GABA}}$ of PVN presympathetic neurons in hypertension. $\boldsymbol{a}$, Original traces of GABA currents recorded using the perforated patch-clamp technique at different holding potentials. $\boldsymbol{b}, I-V$ plots and mean changes show the $E_{\mathrm{GABA}}$ of labeled PVN neurons treated with vehicle ( $n=8$ neurons), bumetanide (20 $\mu \mathrm{m}$ for $2-4 \mathrm{~h}, n=7$ neurons) or furosemide ( $200 \mu \mathrm{m}$ for $2-4 \mathrm{~h}, n=8$ neurons) from SHRs. c, Original recordings and mean membrane potential changes induced by GABA puff application of labeled PVN neuron treated with vehicle ( $n=8$ neurons), bumetanide ( $n=8$ neurons) or furosemide ( $n=9$ neurons) from SHRs. The downward arrows indicate the time of puff GABA application. $\boldsymbol{d}$, Cell-attached recordings and the mean firing activity of labeled PVN neurons before and during application of bicuculline ( $n=9$ neurons) or gabazine ( $n=8$ neurons) in bumetanide-treated brain slices from SHRs. BUM, Bumetanide; FURO, furosemide. ${ }^{* *} p<0.01,{ }^{* * *} p<0.001$, compared with the value in vehicle-treated SHRs; ${ }^{\# \#} p<0.01$, compared with the corresponding baseline value.

tial of spinally projecting PVN neurons ( $n=7$ neurons; $p<0.01$, $t=4.82$, df $=6$; Fig. $4 c$ ). Furthermore, treating the SHR brain slices with bumetanide not only reduced the basal firing rate but also restored the stimulatory effects of bicuculline and gabazine on the firing activity of PVN neurons ( $n=8$ neurons; $p<0.001$, $t=5.54$, df = 7; Fig. $4 d$ ). These findings indicate that increased NKCC1 activity disrupts the chloride homeostasis of PVN presympathetic neurons in hypertension.

\section{Upregulation of NKCC1 in the PVN in hypertension}

To determine whether NKCC1 is upregulated in the PVN in hypertension, we micro-punched PVN tissues and used immuno-
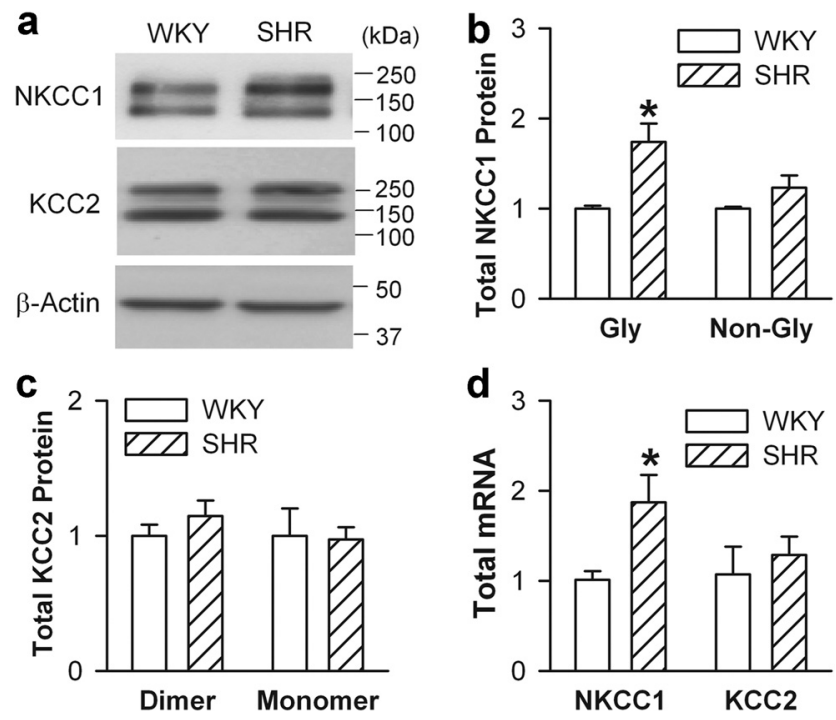

Figure 5. NKCC1 is upregulated in the PVN in hypertension. $\boldsymbol{a}$, Immunoblots of NKCC1 and KCC2 proteins in the PVN from WKY rats and SHRs. $\boldsymbol{b}, \boldsymbol{c}$, Quantification of NKCC1 (b) and KCC2 (c) protein levels in the PVN from WKY rats and SHRs ( $n=4$ samples in each group). $\boldsymbol{d}$, Quantification of NKCC1 and KCC2 mRNA levels in the PVN from WKY rats and SHRs ( $n=4$ samples in each group). The molecular weight is indicated to the right of the gel images. Gly, Glycosylated NKCC1; Non-Gly, nonglycosylated NKCC1. Four samples, each consisting of PVN tissues from 3 rats, were used in each group. ${ }^{*} p<0.05$, compared with the WKY group.

blot analysis to assess their NKCC1 protein levels. We found two NKCC1 protein bands at $\sim 170 \mathrm{kDa}$ and $\sim 135 \mathrm{kDa}$ in the PVN from WKY rats and SHRs (Fig. 5a). The larger protein band represented glycosylated NKCC1 proteins (Plotkin et al., 1997a,b). The level of glycosylated NKCC1 protein, but not that of nonglycosylated NKCC1 protein, was significantly higher in SHRs than in WKY rats (Fig. $5 a, b$ ). We also detected two KCC2 protein bands at $\sim 270$ and $\sim 140 \mathrm{kDa}$ (Fig. $5 a, c$ ), which represented KCC2 proteins' dimeric and monomeric forms, respectively (Williams et al., 1999; Blaesse et al., 2006; Hewitt et al., 2009). However, the levels of dimeric and monomeric KCC2 proteins in the PVN in WKY rats and SHRs did not differ significantly (Fig. $5 a, c$ ).

Real-time PCR analysis of the micro-punched PVN tissues from WKY rats and SHRs revealed that the mRNA level of NKCC1 in the PVN was significantly higher in SHRs than in WKY rats (Fig. 5d). However, the mRNA levels of KCC2 in WKY rats and SHRs did not differ significantly (Fig. $5 d$ ). These data indicate that $\mathrm{NKCC} 1$ in the $\mathrm{PVN}$ is upregulated in hypertension.

\section{NKCC1 glycosylation contributes to the depolarizing shift in} the $E_{\mathrm{GABA}}$ and diminished synaptic inhibition in hypertension NKCC1 activity is largely determined by the amount of NKCC1 proteins present on the plasma membrane and post-translational modifications. We first quantified the NKCC1 membrane proteins in the PVN tissues. Surprisingly, we detected only one NKCC1 band at $\sim 170 \mathrm{kDa}$ (glycosylated NKCC1) in the PVN membrane fraction. The membrane level of glycosylated NKCC1 was significantly greater in SHRs than in WKY rats (Fig. 6a,b). To determine whether the membrane NKCC1 proteins were indeed the glycosylated form of NKCC1, we treated the PVN membrane samples from SHRs with the deglycosylation agent PNGase F $\left(25,000 \mathrm{U} / \mathrm{ml}\right.$ at $37^{\circ} \mathrm{C}$ for $\left.1 \mathrm{~h}\right)$ (Gerelsaikhan et al., 2006). After deglycosylation treatment, we detected only a lower protein band $(\sim 135 \mathrm{kDa})$ in the membrane fraction, which represented the nonglycosylated form of NKCC1 (Fig. 6a). These results indicate 

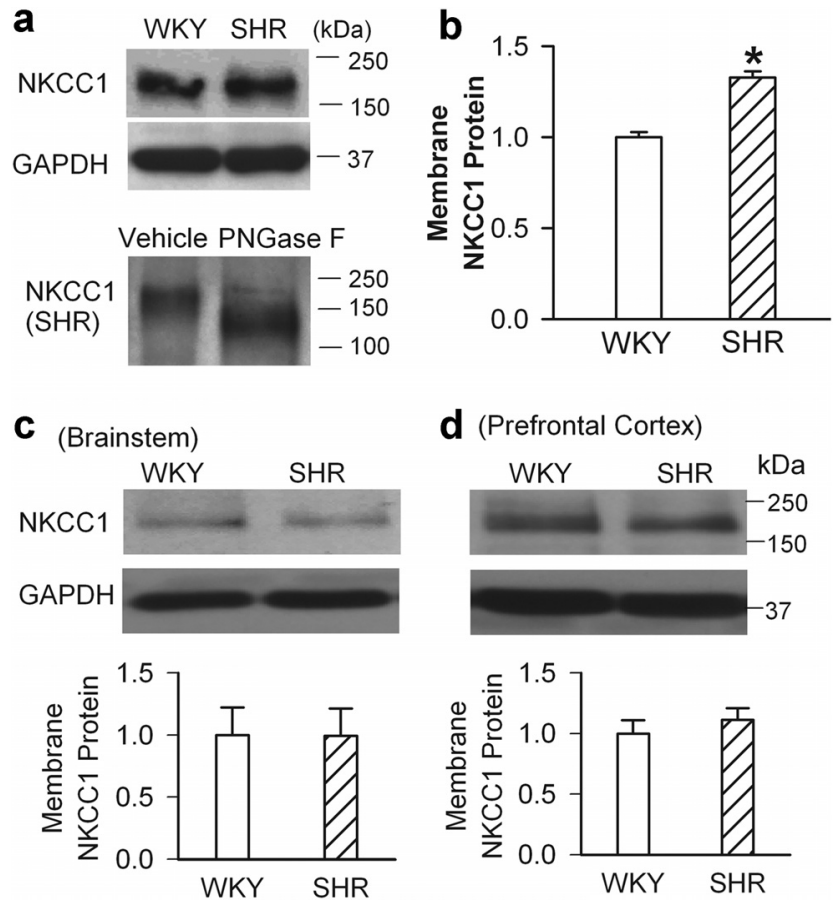

Figure 6. Membrane NKCC1 is highly glycosylated in the PVN in hypertension. $\boldsymbol{a}$, Western blots of NKCC1 membrane proteins in the PVN from WKY rats and SHRs (top) andNKCC1 membrane protein in SHRs treated with vehicle and PNGase F (bottom). $\boldsymbol{b}$, Quantification of the NKCC1 membrane protein level in the PVN in WKY rats and SHRs ( $n=4$ samples in each group). $\boldsymbol{c}, \boldsymbol{d}$, Western blots and quantification show the membrane protein levels of NKCC1 in the brainstem (c) and prefrontal cortex (d) in SHRs and WKY rats ( $n=4$ samples in each group). The molecular weight markers are indicated to the right of the gel. In these the protein assays, 4 samples, each consisting of PVN tissues from 3 rats, were used in each group. ${ }^{*} p<0.05$, compared with the WKY group. Error bars represent SEM.

that the NKCC1 membrane protein in the PVN is highly glycosylated and increased in hypertension.

We also measured the NKCC1 membrane protein levels in the brainstem and prefrontal cortex to determine whether the level of glycosylated NKCC1 proteins is increased in other brain regions in SHRs. The glycosylated NKCC1 membrane protein levels in the brainstem and prefrontal cortex from WKY rats and SHRs did not differ significantly (Fig. $6 c, d$ ). In addition, the $E_{\mathrm{GABA}}$ of pyramidal neurons in the prefrontal cortex did not differ significantly between WKY rats $(-75.06 \pm 0.43 \mathrm{mV})$ and SHRs $(-74.48 \pm$ $0.72 \mathrm{mV} ; n=6$ neurons in each group). These results indicate that increased glycosylation of NKCC1 proteins is not a general phenomenon in the brain in hypertension.

$\mathrm{N}$-glycosylation is important for the membrane expression and function of some transmembrane transporters such as glycine transporter-2 (Martínez-Maza et al., 2001). However, the impact of $N$-glycosylation on neuronal NKCC1 function remains unknown. To determine whether $N$-linked glycosylation of the NKCC1 protein is responsible for increased NKCC1 activity and altered chloride homeostasis in PVN presympathetic neurons in hypertension, we examined the $E_{\mathrm{GABA}}$ and GABAergic control of spinally projecting PVN neurons after incubating brain slices from SHRs with the $N$-linked glycosylation inhibitor tunicamycin (50 nM for 2 h) (Matthies et al., 1999). Treatment with tunicamycin not only prevented the depolarizing shift in the $E_{\mathrm{GABA}}$ $(p<0.001, F=24.62, \mathrm{df}=19)$ but also normalized the GABA inhibition $(p<0.001, F=23.27, \mathrm{df}=19)$ of PVN neurons in SHRs ( $n=7$ neurons in each group; Fig. $7 a-d$ ). Moreover, in brain slices treated with tunicamycin, bumetanide had no further
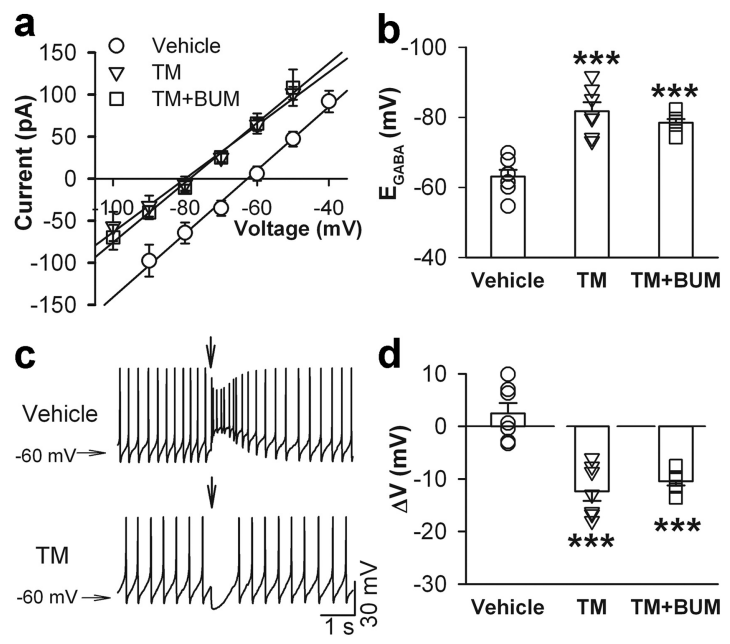

Figure 7. Inhibition of $N$-glycosylation of NKCC 1 normalizes $G A B A$ inhibition and the $E_{\mathrm{GABA}}$ of PVN presympathetic neurons in hypertension. $\boldsymbol{a}, \boldsymbol{b}$, Changes in GABA currents recorded at different holding potentials $(\boldsymbol{a})$ and the $E_{\mathrm{GABA}}(\boldsymbol{b})$ of labeled PVN neurons in SHR brain slices treated with vehicle ( $n=7$ neurons), tunicamycin ( $n=7$ neurons), or tunicamycin plus bumetanide ( $n=6$ neurons). $\boldsymbol{c}, \boldsymbol{d}$, Original recordings (c) and mean changes in the membrane potential (d) induced by puff GABA application to labeled PVN neurons of SHRs. TM, Tunicamycin. ${ }^{* * *} p<$ 0.001 , compared with the vehicle-treated group.

effects on the $E_{\mathrm{GABA}}$ and GABA-induced hyperpolarization of PVN neurons ( $n=6$ neurons; Fig. $7 a-d)$. These findings suggest that NKCC1 $\mathrm{N}$-glycosylation plays an essential role in increased NKCC1 activity and diminished GABAergic inhibition of PVN presympathetic neurons in hypertension.

\section{NKCC1 upregulation contributes to increased sympathetic vasomotor tone in hypertension}

We then determined whether increased NKCC1 activity contributes to diminished GABA inhibition of the sympathetic outflow in hypertension. The NKCC1 inhibitor bumetanide $(200 \mu \mathrm{M}$ in $10 \mu \mathrm{l} ; 3$ times at an interval of $30 \mathrm{~min}$ ) was injected via an intracerebroventricular catheter. Bumetanide treatment significantly decreased LSNA, ABP, and HR in SHRs ( $n=11$ rats; Fig. $8 a-e)$. However, intracerebroventricular injection of the vehicle (0.5\% dimethyl sulfoxide [DMSO]) did not significantly alter the ABP, HR, or LSNA in another set of SHRs ( $n=9$ rats; Fig. $8 a-e)$. The specific $\mathrm{GABA}_{\mathrm{A}}$ receptor agonist muscimol (1.0 nmol, $50 \mathrm{nl}$ ) was microinjected into the PVN in SHRs treated with vehicle or bumetanide. Microinjection of muscimol into the PVN produced a significantly greater decrease in LSNA, $\mathrm{ABP}$, and HR in bumetanide-treated SHRs than in vehicletreated SHRs (Fig. $8 c-f$ ). These data indicate that increased NKCC1 activity diminishes GABA inhibition of sympathetic drive in the PVN in hypertension.

\section{Discussion}

The sympathetic drive emanating from the brain is augmented and is critically involved in the development of hypertension (Ciriello et al., 1984; Ciriello, 1987; Eilam et al., 1991; Schlaich et al., 2004). Increased sympathetic nerve activity can cause chronically elevated systemic blood pressure through direct vasoconstriction and by increasing the rate and contractility of the myocardium (Esler, 2000). Also, increased renal sympathetic nerve activity causes renin secretion, which activates the reninangiotensin system, leading to angiotensin II-induced vasoconstriction and antinatriuresis. The hypothalamic PVN neurons regulate sympathetic outflow through their projections to the 
a
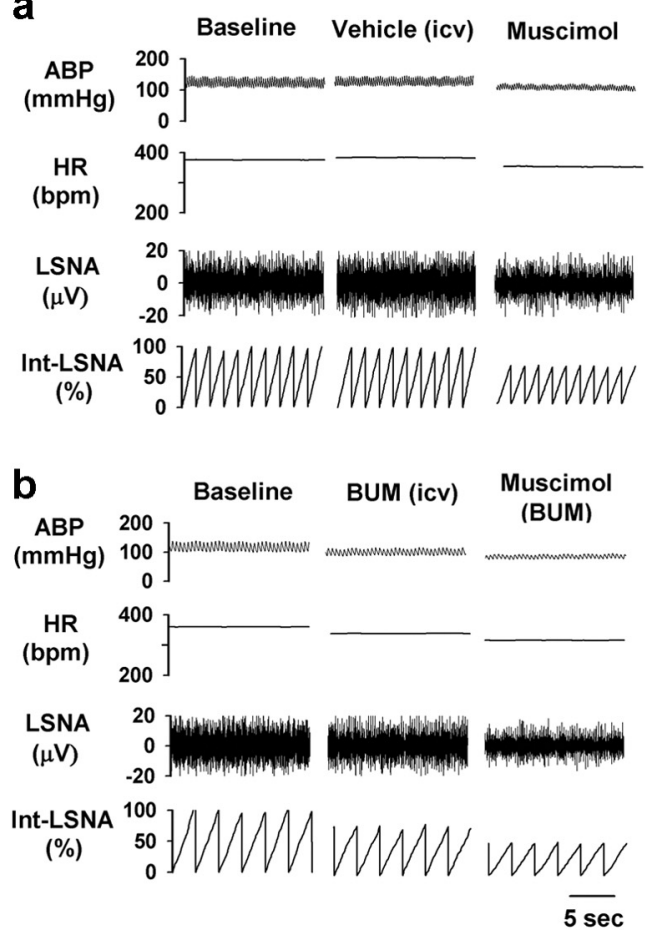

C
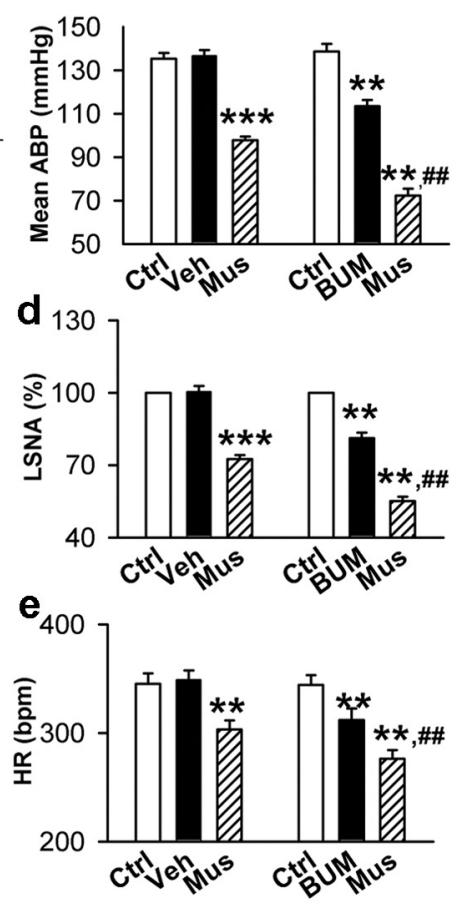

f
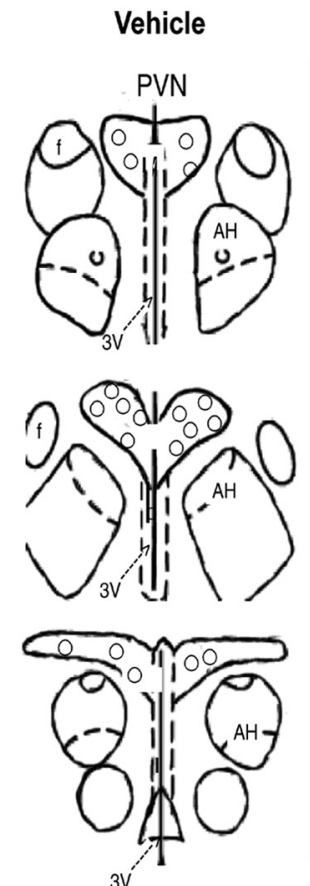

$3 v^{\prime}$
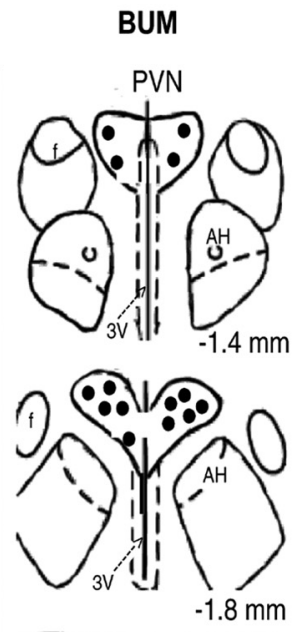

$-1.8 \mathrm{~mm}$

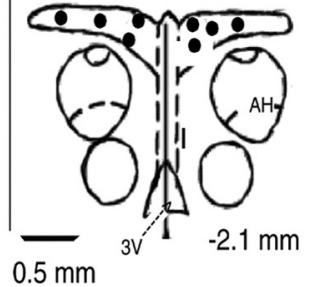

Figure 8. NKCC1 inhibition reduces sympathetic vasomotor tone and enhances sympathoinhibitory responses to $\mathrm{GABA}_{\mathrm{A}}$ receptor activation in the PVN in hypertension. $\boldsymbol{a}, \boldsymbol{b}$, Representative recordings show the effect of bumetanide $(0.1 \mathrm{nmol}, 2 \mu$ l, i.c.v. $)$ and bilateral microinjection of muscimol ( $1.0 \mathrm{nmol}, 50 \mathrm{nl})$ into the PVN on the ABP, HR, and LSNA in SHRs. $c-e$, Changes in the mean $\operatorname{ABP}(\boldsymbol{c})$, LSNA (d) , and HR (e) in response to microinjection of muscimol into the PVN after treatment with bumetanide (BUM, $n=11$ rats) or vehicle (Veh, $n=9$ rats). $\boldsymbol{f}$, Schematic drawings show the location of muscimol (MUS) microinjection sites in the PVN ofSHRs treated with vehicle (O) or bumetanide (O). Ctrl, Control; $3 \mathrm{~V}$, third ventricle; AH, anterior hypothalamus. ${ }^{* *} p<0.01,{ }^{* * *} p<$ 0.001 , compared with the baseline control in each group. ${ }^{\#} p<0.01$, compared with the corresponding value in the vehicle group.

spinal cord and the RVLM (Swanson and Sawchenko, 1983; Ranson et al., 1998), and hyperactivity of PVN presympathetic neurons increases sympathetic vasomotor tone, thereby contributing to the development of hypertension (Yamori and Okamoto, 1969; Ciriello et al., 1984; Eilam et al., 1991). For example, transection of the brain caudal to the hypothalamus reduces ABP in SHRs, but not in normotensive WKY rats (Yamori and Okamoto, 1969). Also, transplantation of embryonic hypothalamic tissues of SHRs into the brain of adult normotensive rats results in the development of hypertension (Eilam et al., 1991). Although the loss of GABAergic synaptic inhibition in the PVN can increase the excitability of PVN presympathetic neurons and sympathetic drive in hypertension (Li and Pan, 2006, 2007a), the mechanisms underlying diminished GABA inhibition in hypertension remain unknown. One unexplored potential mechanism underlying impaired GABAergic inhibition in the PVN in hypertension involves altered chloride homeostasis of PVN neurons. In the present study, we present novel evidence showing that the chloride homeostasis of PVN presympathetic neurons is disrupted and caused by increased NKCC1 activity, which contributes to diminished GABAergic inhibition and increased sympathetic outflow in hypertension.

GABA is the primary inhibitory neurotransmitter in the adult brain. The $\mathrm{GABA}_{\mathrm{A}}$ receptor is predominantly permeable to $\mathrm{Cl}^{-}$, and GABA normally inhibits neuronal excitability by hyperpolarizing the cell membrane and by activation of a shunting conductance, which inhibits propagation of EPSPs along the dendrites of neurons. Increased $\left[\mathrm{Cl}^{-}\right]_{\mathrm{i}}$, reflected by a depolarizing shift in the $E_{\mathrm{GABA}}$, can switch GABAergic inhibition to excitation in epilepsy (Pathak et al., 2007) and neuropathic pain (Coull et al., 2003). In the present study, using both cell-attached and gramicidin-perforated patch-clamp recordings, we show that a depolarizing shift in $E_{\mathrm{GABA}}$ diminishes GABA inhibition of PVN neurons projecting to the spinal cord or RVLM in SHRs. The derived $\left[\mathrm{Cl}^{-}\right]_{\mathrm{i}}$, calculated by the Nernst equation, in the PVN neurons is significantly greater in SHRs than in WKY rats. The excitatory glutamatergic input in the PVN is augmented and maintains elevated sympathetic vasomotor tone in hypertension (Li and Pan, 2007b; Li et al., 2008). The depolarizing shift in $E_{\mathrm{GABA}}$ will reduce or even convert the inhibitory action of GABA on excitatory inputs such that subthreshold excitations can lead to the generation of action potentials. Although we observed a consistent depolarizing shift in $E_{\mathrm{GABA}}$ of PVN presympathetic neurons in SHRs, direct GABA application caused either a small hyperpolarization or a small depolarization of the membrane potential of these PVN neurons. The net effect of disruption of chloride homeostasis in this population of PVN neurons in hypertension is the loss of GABAergic synaptic inhibition, which could explain why the $\mathrm{GABA}_{\mathrm{A}}$ receptor antagonists had no significant inhibitory effect on the elevated firing activity of PVN neurons in hypertension.

Acute mental stress and chronic hyperosmotic stress can cause a depolarizing shift in $E_{\mathrm{GABA}}$ through decreased KCC2 and increased NKCC1 activity, respectively, in hypothalamic neurons (Hewitt et al., 2009; Kim et al., 2011). Whereas KCC2 extrudes chloride, NKCC1 mediates chloride influx in neurons (Payne et al., 2003; Kahle et al., 2008). Altered chloride homeostasis, resulting from mutation or dysfunction of NKCC1 and/or KCC2, can dramatically change the action of GABA in neurons (Rivera et al., 1999; Payne et al., 2003). In this study, we show that inhibition of KCC2 has no significant effect on the $E_{\mathrm{GABA}}$ in PVN presympathetic neurons from SHRs. In contrast, inhibition of NKCC1 
normalizes the $E_{\mathrm{GABA}}$ and GABA inhibition of the firing activity of PVN presympathetic neurons in SHRs. Consistent with this finding, we show that the mRNA level of NKCC1, but not KCC2, in the PVN is significantly increased in SHRs. We also show that the protein level of NKCC1, but not KCC2, is significantly higher in the PVN in SHRs than in WKY rats. These findings indicate that NKCC1 upregulation disrupts chloride homeostasis of PVN presympathetic neurons in hypertension.

We found unexpectedly that the NKCC1 membrane protein in the PVN is highly glycosylated and significantly increased in SHRs. The structural motif of NKCC1 consists of a high-molecular-mass glycosylated polypeptide processing $12 \alpha$-helical membranespanning domains with several extracellular $N$-linked glycosylation sites (Xu et al., 1994; Park and Saier, 1996). The impact of $N$-linked glycosylation on the function of NKCC1 remains unknown. In this study, we show that inhibiting $N$-linked glycosylation of NKCC1 restores the $E_{\mathrm{GABA}}$ and GABAergic inhibition of PVN neurons in SHRs. Our findings suggest that increased glycosylation of NKCC1 is essential for augmented NKCC1 activity and the loss of synaptic GABA inhibition in the PVN in hypertension. Previous studies have shown that NKCC1 is phosphorylated by Ste20-related proline/ alanine-rich kinase (SPAK) and oxidative stress-responsive kinase 1 (Piechotta et al., 2002; Moriguchi et al., 2005; Geng et al., 2009). The $\mathrm{NKCC1}$ activity is reduced by one half in primary sensory neurons in SPAK-knock-out mice compared with the wide-type control (Geng et al., 2009). Thus, in addition to the control of NKCC1 activity through phosphorylation, $\mathrm{N}$-linked glycosylation of NKCC1 represents another important post-translational mechanism that governs the functional expression of NKCC1 by affecting its intrinsic activity and trafficking into the plasma membrane in the hypothalamus in hypertension.

In addition to having a diuretic effect in the kidney, inhibiting NKCC1 activity with bumetanide could act in the brain to reduce the sympathetic drive (Li et al., 2011). Interestingly, intravenous infusion of bumetanide inhibits NKCC1 to acutely decrease blood pressure, but this hypotensive effect is not due to its action in the kidney (Garg et al., 2007). In the present study, we show that administering bumetanide directly into the brain significantly reduces the LSNA and ABP in SHRs. These data indicate that increased NKCC1 activity is involved in elevating sympathetic vasomotor tone in SHRs and may mediate the hypotensive effect caused by systemic treatment with bumetanide. Furthermore, we show that bumetanide significantly enhances the sympathoinhibitory responses to $\mathrm{GABA}_{\mathrm{A}}$ receptor stimulation in the PVN. Thus, inhibition of NKCC1 activity restores the "normal" GABAergic inhibition of sympathetic vasomotor tone in the PVN in hypertension. Lowering blood pressure with CGx does not affect the positive shift of the $E_{\mathrm{GABA}}$ of $\mathrm{PVN}$ presympathetic neurons in SHRs, suggesting that increased NKCCl activity in PVN presympathetic neurons is not an adaptive response to high blood pressure but rather contributes to the development of hypertension.

In summary, our study provides novel evidence that increased NKCC1 activity and glycosylation disrupts the chloride homeostasis of PVN presympathetic neurons, which contributes to diminished GABAergic inhibition in SHRs. Our findings indicate that increased NKCC1 activity plays a critical role in the hyperactivity of PVN presympathetic neurons and elevated sympathetic vasomotor tone in hypertension. Therefore, our study provides new insights into the key molecular mechanism underlying diminished synaptic inhibition and increased sympathetic drive in hypertension. NKCC1 in the CNS may represent a new target for the treatment of neurogenic hypertension.

\section{References}

Allen AM (2002) Inhibition of the hypothalamic paraventricular nucleus in spontaneously hypertensive rats dramatically reduces sympathetic vasomotor tone. Hypertension 39:275-280.

Anderson EA, Sinkey CA, Lawton WJ, Mark AL (1989) Elevated sympathetic nerve activity in borderline hypertensive humans. Evidence from direct intraneural recordings. Hypertension 14:177-183.

Blaesse P, Guillemin I, Schindler J, Schweizer M, Delpire E, Khiroug L, Friauf E, Nothwang HG (2006) Oligomerization of KCC2 correlates with development of inhibitory neurotransmission. J Neurosci 26:10407-10419.

Bormann J, Hamill OP, Sakmann B (1987) Mechanism of anion permeation through channels gated by glycine and gamma-aminobutyric acid in mouse cultured spinal neurones. J Physiol 385:243-286.

Ciriello J (1987) Forebrain mechanisms in neurogenic hypertension. Can J Physiol Pharmacol 65:1580-1583.

Ciriello J, Kline RL, Zhang TX, Caverson MM (1984) Lesions of the paraventricular nucleus alter the development of spontaneous hypertension in the rat. Brain Res 310:355-359.

Coull JA, Boudreau D, Bachand K, Prescott SA, Nault F, Sík A, De Koninck P, De Koninck Y (2003) Trans-synaptic shift in anion gradient in spinal lamina I neurons as a mechanism of neuropathic pain. Nature 424:938-942.

Delpy A, Allain AE, Meyrand P, Branchereau P (2008) NKCC1 cotransporter inactivation underlies embryonic development of chloridemediated inhibition in mouse spinal motoneuron. J Physiol 586:1059-1075.

Dzhala VI, Talos DM, Sdrulla DA, Brumback AC, Mathews GC, Benke TA, Delpire E, Jensen FE, Staley KJ (2005) NKCC1 transporter facilitates seizures in the developing brain. Nat Med 11:1205-1213.

Ebihara S, Shirato K, Harata N, Akaike N (1995) Gramicidin-perforated patch recording: GABA response in mammalian neurones with intact intracellular chloride. J Physiol 484:77-86.

Eilam R, Malach R, Bergmann F, Segal M (1991) Hypertension induced by hypothalamic transplantation from genetically hypertensive to normotensive rats. J Neurosci 11:401-411.

Esler M (2000) The sympathetic system and hypertension. Am J Hypertens 13:99S-105S.

Garg P, Martin CF, Elms SC, Gordon FJ, Wall SM, Garland CJ, Sutliff RL, O'Neill WC (2007) Effect of the Na-K-2Cl cotransporter NKCC1 on systemic blood pressure and smooth muscle tone. Am J Physiol Heart Circ Physiol 292:H2100-H2105.

Geng Y, Hoke A, Delpire E (2009) The Ste20 kinases Ste20-related prolinealanine-rich kinase and oxidative-stress response 1 regulate NKCC1 function in sensory neurons. J Biol Chem 284:14020-14028.

Gerelsaikhan T, Parvin MN, Turner RJ (2006) Biogenesis and topology of the secretory $\mathrm{Na}^{+}-\mathrm{K}^{+}-2 \mathrm{Cl}^{-}$cotransporter (NKCC1) studied in intact mammalian cells. Biochemistry 45:12060-12067.

Greenwood JP, Stoker JB, Mary DA (1999) Single-unit sympathetic discharge: quantitative assessment in human hypertensive disease. Circulation 100:1305-1310.

Grover LM, Lambert NA, Schwartzkroin PA, Teyler TJ (1993) Role of $\mathrm{HCO} 3$ - ions in depolarizing GABAA receptor-mediated responses in pyramidal cells of rat hippocampus. J Neurophysiol 69:1541-1555.

Hewitt SA, Wamsteeker JI, Kurz EU, Bains JS (2009) Altered chloride homeostasis removes synaptic inhibitory constraint of the stress axis. Nat Neurosci 12:438-443.

Judy WV, Watanabe AM, Henry DP, Besch HR Jr, Murphy WR, Hockel GM (1976) Sympathetic nerve activity: role in regulation of blood pressure in the spontaneously hypertensive rat. Circ Res 38:21-29.

Kahle KT, Staley KJ, Nahed BV, Gamba G, Hebert SC, Lifton RP, Mount DB (2008) Roles of the cation-chloride cotransporters in neurological disease. Nat Clin Pract Neurol 4:490-503.

Kaila K, Voipio J (1987) Postsynaptic fall in intracellular pH induced by GABA-activated bicarbonate conductance. Nature 330:163-165.

Kaila K, Voipio J, Paalasmaa P, Pasternack M, Deisz RA (1993) The role of bicarbonate in GABAA receptor-mediated IPSPs of rat neocortical neurones. J Physiol 464:273-289.

Kaila K, Lamsa K, Smirnov S, Taira T, Voipio J (1997) Long-lasting GABA-mediated depolarization evoked by high-frequency stimulation in pyramidal neurons of rat hippocampal slice is attributable to a network-driven, bicarbonate-dependent $\mathrm{K}+$ transient. J Neurosci 17:7662-7672. 
Kakazu Y, Uchida S, Nakagawa T, Akaike N, Nabekura J (2000) Reversibility and cation selectivity of the $\mathrm{K}(+)-\mathrm{Cl}(-)$ cotransport in rat central neurons. J Neurophysiol 84:281-288.

Kannan H, Hayashida Y, Yamashita H (1989) Increase in sympathetic outflow by paraventricular nucleus stimulation in awake rats. Am J Physiol 256:R1325-R1330.

Kim JS, Kim WB, Kim YB, Lee Y, Kim YS, Shen FY, Lee SW, Park D, Choi HJ, Hur J, Park JJ, Han HC, Colwell CS, Cho YW, Kim YI (2011) Chronic hyperosmotic stress converts GABAergic inhibition into excitation in vasopressin and oxytocin neurons in the rat. J Neurosci 31:13312-13322.

Kyrozis A, Reichling DB (1995) Perforated-patch recording with gramicidin avoids artifactual changes in intracellular chloride concentration. J Neurosci Methods 57:27-35.

Li DP, Pan HL (2005) Angiotensin II attenuates synaptic GABA release and excites paraventricular-rostral ventrolateral medulla output neurons. J Pharmacol Exp Ther 313:1035-1045.

Li DP, Pan HL (2006) Plasticity of GABAergic control of hypothalamic presympathetic neurons in hypertension. Am J Physiol Heart Circ Physiol 290:H1110-H1119.

Li DP, Pan HL (2007a) Role of gammaGABAA and GABAB receptors in paraventricular nucleus in control of sympathetic vasomotor tone in hypertension. J Pharmacol Exp Ther 320:615-626.

Li DP, Pan HL (2007b) Glutamatergic inputs in the hypothalamic paraventricular nucleus maintain sympathetic vasomotor tone in hypertension. Hypertension 49:916-925.

Li DP, Chen SR, Pan HL (2003) Angiotensin II stimulates spinally projecting paraventricular neurons through presynaptic disinhibition. J Neurosci 23:5041-5049.

Li DP, Yang Q, Pan HM, Pan HL (2008) Pre- and postsynaptic plasticity underlying augmented glutamatergic inputs to hypothalamic presympathetic neurons in spontaneously hypertensive rats. J Physiol 586:1637-1647.

Li DP, Byan HS, Pan HL (2012) Switch to glutamate receptor 2-lacking AMPA receptors increases neuronal excitability in hypothalamus and sympathetic drive in hypertension. J Neurosci 32:372-380.

Li Y, Cleary R, Kellogg M, Soul JS, Berry GT, Jensen FE (2011) Sensitive isotope dilution liquid chromatography/tandem mass spectrometry method for quantitative analysis of bumetanide in serum and brain tissue. J Chromatogr B Analyt Technol Biomed Life Sci 879:998-1002.

Lytle C, Xu JC, Biemesderfer D, Forbush B 3rd (1995) Distribution and diversity of $\mathrm{Na}-\mathrm{K}-\mathrm{Cl}$ cotransport proteins: a study with monoclonal antibodies. Am J Physiol 269:C1496-1505.

Mancia G, Grassi G, Giannattasio C, Seravalle G (1999) Sympathetic activation in the pathogenesis of hypertension and progression of organ damage. Hypertension 34:724-728.

Martin DS, Haywood JR (1993) Hemodynamic responses to paraventricular nucleus disinhibition with bicuculline in conscious rats. Am J Physiol 265:H1727-H1733.

Martínez-Maza R, Poyatos I, López-Corcuera B, Núñez E, Giménez C, Zafra F, Aragón C (2001) The role of $N$-glycosylation in transport to the plasma membrane and sorting of the neuronal glycine transporter GLYT2. J Biol Chem 276:2168-2173.

Matthies H Jr, Kretlow J, Matthies H, Smalla KH, Staak S, Krug M (1999) Glycosylation of proteins during a critical time window is necessary for the maintenance of long-term potentiation in the hippocampal CA1 region. Neuroscience 91:175-183.

Mercado A, Mount DB, Gamba G (2004) Electroneutral cation-chloride cotransporters in the central nervous system. Neurochem Res 29:17-25.

Moriguchi T, Urushiyama S, Hisamoto N, Iemura S, Uchida S, Natsume T,
Matsumoto K, Shibuya H (2005) WNK1 regulates phosphorylation of cation-chloride-coupled cotransporters via the STE20-related kinases, SPAK and OSR1. J Biol Chem 280:42685-42693.

Park JH, Saier MH Jr (1996) Phylogenetic, structural and functional characteristics of the Na-K-Cl cotransporter family. J Membr Biol 149:161-168.

Pathak HR, Weissinger F, Terunuma M, Carlson GC, Hsu FC, Moss SJ, Coulter DA (2007) Disrupted dentate granule cell chloride regulation enhances synaptic excitability during development of temporal lobe epilepsy. J Neurosci 27:14012-14022.

Paxinos G, Watson C (1998) The rat brain in stereotaxic coordinates, Ed 4. San Diego: Academic.

Payne JA, Stevenson TJ, Donaldson LF (1996) Molecular characterization of a putative $\mathrm{K}-\mathrm{Cl}$ cotransporter in rat brain. A neuronal-specific isoform. J Biol Chem 271:16245-16252.

Payne JA, Rivera C, Voipio J, Kaila K (2003) Cation-chloride cotransporters in neuronal communication, development and trauma. Trends Neurosci 26:199-206.

Piechotta K, Lu J, Delpire E (2002) Cation chloride cotransporters interact with the stress-related kinases Ste20-related proline-alanine-rich kinase (SPAK) and oxidative stress response 1 (OSR1). J Biol Chem 277:50812-50819.

Plotkin MD, Snyder EY, Hebert SC, Delpire E (1997a) Expression of the $\mathrm{Na}-\mathrm{K}-2 \mathrm{Cl}$ cotransporter is developmentally regulated in postnatal rat brains: a possible mechanism underlying GABA's excitatory role in immature brain. J Neurobiol 33:781-795.

Plotkin MD, Kaplan MR, Peterson LN, Gullans SR, Hebert SC, Delpire E (1997b) Expression of the $\mathrm{Na}(+)-\mathrm{K}(+)-2 \mathrm{Cl}$ - cotransporter BSC2 in the nervous system. Am J Physiol 272:C173-C183.

Pyner S, Coote JH (2000) Identification of branching paraventricular neurons of the hypothalamus that project to the rostroventrolateral medulla and spinal cord. Neuroscience 100:549-556.

Ranson RN, Motawei K, Pyner S, Coote JH (1998) The paraventricular nucleus of the hypothalamus sends efferents to the spinal cord of the rat that closely appose sympathetic preganglionic neurones projecting to the stellate ganglion. Exp Brain Res 120:164-172.

Rivera C, Voipio J, Payne JA, Ruusuvuori E, Lahtinen H, Lamsa K, Pirvola U, Saarma M, Kaila K (1999) The K+/Cl- co-transporter KCC2 renders GABA hyperpolarizing during neuronal maturation. Nature 397:251-255.

Schlaich MP, Lambert E, Kaye DM, Krozowski Z, Campbell DJ, Lambert G, Hastings J, Aggarwal A, Esler MD (2004) Sympathetic augmentation in hypertension: role of nerve firing, norepinephrine reuptake, and Angiotensin neuromodulation. Hypertension 43:169-175.

Sung KW, Kirby M, McDonald MP, Lovinger DM, Delpire E (2000) Abnormal GABAA receptor-mediated currents in dorsal root ganglion neurons isolated from Na-K-2Cl cotransporter null mice. J Neurosci 20:7531-7538.

Swanson LW, Sawchenko PE (1983) Hypothalamic integration: organization of the paraventricular and supraoptic nuclei. Annu Rev Neurosci 6:269-324.

Williams JR, Sharp JW, Kumari VG, Wilson M, Payne JA (1999) The neuron-specific $\mathrm{K}-\mathrm{Cl}$ cotransporter, $\mathrm{KCC} 2$. Antibody development and initial characterization of the protein. J Biol Chem 274:12656-12664.

Xu JC, Lytle C, Zhu TT, Payne JA, Benz E Jr, Forbush B 3rd (1994) Molecular cloning and functional expression of the bumetanide-sensitive $\mathrm{Na}$ K-Cl cotransporter. Proc Natl Acad Sci U S A 91:2201-2205.

Yamori Y, Okamoto K (1969) Hypothalamic tonic regulation of blood pressure in spontaneously hypertensive rats. Jpn Circ J 33:509-519.

Ye ZY, Li DP, Li L, Pan HL (2011) Protein kinase CK2 increases glutamatergic input in the hypothalamus and sympathetic vasomotor tone in hypertension. J Neurosci 31:8271-8279. 